\title{
Most ornamental plants on sale in garden centres are unattractive to flower-visiting insects
}

\author{
Mihail Garbuzov ${ }^{\text {Corresp., }}{ }^{1}$, Karin Alton ${ }^{1}{ }^{\text {, Francis L. W. Ratnieks }}{ }^{1}$ \\ ${ }^{1}$ Laboratory of Apiculture \& Social Insects, School of Life Sciences, University of Sussex, Brighton, East Sussex, United Kingdom \\ Corresponding Author: Mihail Garbuzov \\ Email address: m.garbuzov@sussex.ac.uk
}

Background. Gardeners and park managers seeking to support biodiversity in urban areas often plant ornamentals attractive to flower-visiting insects. There is a huge diversity of garden plant varieties, and some recommendations are available as to which are attractive to insects. However, these are largely not based on rigorous empirical data. An important factor in consumer choice is the range of varieties available for purchase. In the UK, garden centres are a key link in the supply chain between growers and private gardens. This study is the first to determine the proportions of flowering ornamentals being sold that are attractive to flower-visiting insects.

Methods. We surveyed six garden centres in England, UK, each over 2 days in 2015, by making 12 counts of insects visiting patches of each ornamental plant on display for sale that was in bloom. To provide a consistent baseline among different locations, we brought with us and surveyed marjoram (Origanum vulgare) plants in pots, which are known to be attractive to a wide range of flower-visiting insects. The attractiveness of plant varieties to insects was then expressed in two ways: the absolute number and relative to that on marjoram ('marjoram score'), both per unit area of plant cover. In addition, we noted whether each variety was recommended as pollinator-friendly either via a symbol on the label, or by being included in the Royal Horticultural Society's 'Perfect for Pollinators' list.

Furthermore, we compared the attractiveness of plants that are typically grown for more than one year versus only one year.

Results. We surveyed 59-74 plant varieties in bloom across the six garden centres. In each garden centre, the distributions of variety attractiveness were highly skewed to the right, with most varieties being relatively unattractive, and few varieties highly attractive to flower-visiting insects. The median attractiveness of varieties with a recommendation was $4.2 \times$ higher than that of varieties without. But, due the large variation there was a substantial number of both poor varieties that had a recommendation and good varieties that did not. Median attractiveness of multi-year plants was $1.6 \times$ that of single-year plants, with a similar overlap in distributions.

Discussion. Our study demonstrates the practicality of carrying out plant surveys in garden centres. Garden centres display large numbers of varieties for sale, most of which are in bloom. Furthermore, data gathered in garden centres appear to correlate well with data gathered in two previous studies in Sussex for plants established in gardens. Although it is unclear whether the varieties being sold in garden centres are a fair representation of varieties that are actually grown by gardeners, our results suggest that there might be considerable scope for making parks and gardens considerably more insect-friendly through judicious variety choices. 
1 Most ornamental plants on sale in garden centres are unattractive to flower-visiting insects

2 Mihail Garbuzov ${ }^{1}$, Karin Alton ${ }^{1}$, Francis L. W. Ratnieks ${ }^{1}$

3

$4{ }^{1}$ Laboratory of Apiculture \& Social Insects, School of Life Sciences, University of Sussex,

5 Falmer, Brighton, BN1 9QG, United Kingdom

6

7 Corresponding Author:

8

$9 \quad$ Mihail Garbuzov ${ }^{1}$

10

11 Email address: m.garbuzov@sussex.ac.uk

12 
13 Abstract

Background. Gardeners and park managers seeking to support biodiversity in urban areas often plant ornamentals attractive to flower-visiting insects. There is a huge diversity of garden plant varieties, and some recommendations are available as to which are attractive to insects. However, these are largely not based on rigorous empirical data. An important factor in consumer choice is the range of varieties available for purchase. In the UK, garden centres are a key link in the supply chain between growers and private gardens. This study is the first to determine the proportions of flowering ornamentals being sold that are attractive to flowervisiting insects.

Methods. We surveyed six garden centres in England, UK, each over 2 days in 2015, by making 12 counts of insects visiting patches of each ornamental plant on display for sale that was in bloom. To provide a consistent baseline among different locations, we brought with us and surveyed marjoram (Origanum vulgare) plants in pots, which are known to be attractive to a wide range of flower-visiting insects. The attractiveness of plant varieties to insects was then expressed in two ways: the absolute number and relative to that on marjoram ('marjoram score'), both per unit area of plant cover. In addition, we noted whether each variety was recommended as pollinator-friendly either via a symbol on the label, or by being included in the Royal Horticultural Society's 'Perfect for Pollinators' list. Furthermore, we compared the attractiveness of plants that are typically grown for more than one year versus only one year.

Results. We surveyed 59-74 plant varieties in bloom across the six garden centres. In each garden centre, the distributions of variety attractiveness were highly skewed to the right, with most varieties being relatively unattractive, and few varieties highly attractive to flower- 
visiting insects. The median attractiveness of varieties with a recommendation was $4.2 \times$ higher than that of varieties without. But, due the large variation there was a substantial number of both poor varieties that had a recommendation and good varieties that did not. Median attractiveness of multi-year plants was $1.6 \times$ that of single-year plants, with a similar overlap in distributions.

Discussion. Our study demonstrates the practicality of carrying out plant surveys in garden centres. Garden centres display large numbers of varieties for sale, most of which are in bloom. Furthermore, data gathered in garden centres appear to correlate well with data gathered in two previous studies in Sussex for plants established in gardens. Although it is unclear whether the varieties being sold in garden centres are a fair representation of varieties that are actually grown by gardeners, our results suggest that there might be considerable scope for making parks and gardens considerably more insect-friendly through judicious variety choices.

\section{Introduction}

Pollinating insects appear (Ghazoul, 2015) to be in global decline, with one of the main causes being the loss and degradation of habitats resulting in loss of floral resources (Potts et al., 2010; Kennedy et al., 2013; Goulson et al., 2015). Urban areas, including ornamentals plants in parks and gardens, could play an important role in providing nectar and pollen for flower-visiting insects (Goddard, Dougill \& Benton, 2010; Baldock et al., 2015; Salisbury et al., 2015). Numerous ornamental garden plants are recommended as "friendly" to bees, butterflies and other pollinators, with multiple prominent conservation organizations compiling lists or labelling plants being sold to the public as pollinator-friendly (Garbuzov \& Ratnieks, 2014a). However, in most cases, these recommendations appear not to be based on empirical evidence (Garbuzov \& 
59 Ratnieks, 2014a). A further difficulty in compiling such lists is the fact that many garden plants

60 have many varieties which can vary greatly in their attractiveness to flower-visiting insects. For

61 example, asters are often recommended as pollinator-friendly, while there are hundreds of

62 varieties, which range from highly attractive to non-attractive (Garbuzov \& Ratnieks, 2015). The capacity of urban areas to provide food for flower-visiting insects is affected by the choices of gardeners and garden managers. For example, a survey in one public park in a small town in southern England showed that only a small proportion, 4\%, of the 79 varieties in bloom were highly attractive to flower-visiting insects, most of which were bees and hover flies (Garbuzov, Samuelson \& Ratnieks, 2015). No insects at all were seen on $30 \%$ in 15 counts. This suggests there is scope for making parks and gardens more bee and insect-friendly. In addition, this can be done at zero cost as pollinator-friendly varieties are not more expensive, more difficult to grow or obtain, or less attractive to the human eye (Garbuzov \& Ratnieks, 2015). Furthermore, Lindemann-Mathies \& Marty (2013) have shown that even on the scale of a whole garden, species-rich gardens of high ecological quality tend to be perceived as more aesthetically pleasing by humans. \& Hatherell, 2003), and most private gardeners engage in some form of it (Mew et al., 2003). Motivations for doing so are varied, but notably include a sense of personal wellbeing and moral responsibility for nature (Goddard, Dougill \& Benton, 2013). Indeed, biodiverse nature in urban areas does have a positive influence on physical, psychological and social well-being (Clark et al., 2014; Shanahan et al., 2015). Garden centres are a key part of the supply chain delivering plants from wholesale growers to private gardens. Indeed, garden centres have become a prominent part of the British 
82 shopping and leisure culture. For instance, the largest UK garden centre chain, Wyevale, which

83

84 operates 153 branches nationwide, is estimated to have attracted 46 million visitors and reported an annual revenue of $£ 311$ million in 2015 (Wyevale, 2015). In addition to selling plants, garden centres typically offer a wide range of other goods. These primarily include products associated with gardening, such as gardening tools and equipment, compost, seeds, clothing, as well as the outdoor garden furniture, barbeques, and wildlife-gardening products, such as bird houses and "bee hotels". However, many garden centres have expanded into other household niches, such as food, gifts, clothes, shoes, and even into pet and aquarium products. Almost all garden centres now have restaurants or cafés, as customers tend to make long visits and enjoy lunch or coffee breaks in the interim. In short, garden centres have become a specialized type of shopping centre or mall aimed at attracting customers interested in products for home and garden, for a drink, snack or meal, or for a social outing.

Many gardeners obtain plants from garden centres and similar organizations. As a result, a key factor in the friendliness of gardens to flower-visiting insects is likely to be the plant varieties on sale to the general public. Here, we present the first study of this link in the supply chain by surveying ornamental plants in six retail locations in southern England and quantifying their attractiveness to flower-visiting insects. Garden centres are also practical locations for surveying ornamental plants, as most varieties are sold when they are at or near full bloom, presumably to make them more attractive to customers. Additionally, we determined whether the varieties on sale that had pollinator-friendly symbols on their labels or were included on the UK's Royal Horticultural Society 'Perfect for Pollinators' list (RHS, 2014) are more attractive to flower-visiting insects than non-promoted varieties; and whether hardy multi-year plants are more attractive than bedding plants. Quantifying the attractiveness of plants available to the 
105 public, and understanding how this depends on promotional labelling will hopefully lead to

106 introducing changes that could have tangible benefits for insect conservation in urban areas.

108 Materials \& Methods

109

110

Garden centres

111

112 Six retail locations (five garden centres and one nursery, hereafter 'garden centres', Table 1)

113 were surveyed between 9 July and 19 September 2015. All six garden centres were in East

114 Sussex, southern England, UK, within c. $30 \mathrm{~km}$ of each other. The garden centres were chosen to

115 reflect the diversity of retail types, and included three independent businesses, each with a single

116 site, and three that were branches belonging to medium or large chains. The independents

117 propagated and grew some or all of their stock, while the chains retailed stock brought in from

118 wholesale suppliers.

119

120

Survey methodology

121

122 In each garden centre we only surveyed those plant varieties that were at or near peak bloom and

123 were displayed for sale to the customers. This was between 59 and 74 varieties covering between

12414.7 and $37.6 \mathrm{~m}^{2}$ per garden centre (Table 1). The plants were all being sold in pots and located

125 in the outdoor areas, making them fully accessible to foraging insects. Plant varieties were

126 arranged in groups forming discrete patches made up of a small number of pots, with an average

127 area of $0.23-0.55 \mathrm{~m}^{2}$ per garden centre. Previous research has found that flower patch size does 
128 not affect the number of insects attracted per unit area in the range $0.1-3.1 \mathrm{~m}^{2}$ (Garbuzov,

129 Madsen \& Ratnieks, 2015), which makes it possible to make unbiased comparisons of varieties

130 in patches of different areas.

131 In each garden centre, the survey took two days. On day 1, we made a list of all suitable

132 plant varieties present and measured their patch areas. On day 2, we made 12 counts of insects

133 visiting patches of each variety during one day between 10:00 - 16:30 BST at 30-minute

134 intervals. At each count, the insects foraging in each patch were identified by eye, without

135 capture, into the following categories: (i) honey bee, Apis mellifera, (ii) bumble bees, Bombus

136 spp., and sub-groups after Fussell \& Corbet (1992), (iii) other bees, non-Apis and non-Bombus

137 Anthophila, (iv) hover flies, Diptera: Syrphidae, (v) other flies, non-syrphid Diptera, (vi)

138 butterflies \& moths, Lepidoptera, with butterflies identified to species, (vii) wasps, both social

139 and solitary species and (viii) all other insects. The attractiveness of plants to insects was then

140 expressed as the mean number of insects per count per $\mathrm{m}^{2}$. When plants being surveyed were

141 purchased by customers during the course of the count day, the patch area was re-measured and

142 the calculation adjusted accordingly.

Marjoram baseline

To provide a consistent baseline across the six garden centres, we also surveyed two flowering

147 patches of marjoram, Origanum vulgare, each with an area of $0.45 \mathrm{~m}^{2}$ and consisting of six $10 \mathrm{~L}$ 148 pots. We brought these plants in ourselves and set them up the day before counting began to 149 allow time for insects to discover them. The two marjoram patches were included in the counting 150 routine with all other plant varieties. In this way, the attractiveness of the other varieties could 
151 also be expressed relative to marjoram, hereafter the 'marjoram score'. Marjoram was chosen as

152 it is highly attractive to a wide range of flower-visiting insects (Garbuzov \& Ratnieks, 2014b;

153 Shackleton \& Ratnieks, 2016).

154

155

Pollinator-friendly recommendations and plant longevity

156

157 We determined whether each variety (a) was present on the UK's Royal Horticultural Society's

158 'Perfect for Pollinators' list (RHS, 2014), one of the longest and most authoritative lists of its

159 kind (Garbuzov \& Ratnieks, 2014a), or (b) had any bee- or pollinator-friendly symbol or logo on

160 the pot or label, including the RHS Perfect for Pollinators logo (Fig. 1). There was some overlap

161 between the two categories.

162 In addition, we classified plant longevity into two categories: (a) multi-year: plants that

163 survive for more than one season in Britain, which includes shrubs (e.g. Buddleja, Lavandula)

164 and fully-hardy herbaceous perennials (e.g. Helenium, Salvia) and biennials (e.g. Digitalis); (b)

165 bedding plants: these typically survive for only one season, and include annuals (e.g. Petunia,

166 Viola) plus half-hardy and tender perennials (e.g. Pelargonium, Dahlia) and biennials (e.g.

167 Rudbeckia hirta). Full hardiness was defined as hardiness through most of the UK,

168 corresponding to the RHS hardiness rating category H4 (down to -10 to $-5^{\circ} \mathrm{C}$ ) (RHS, 2016).

169

170 Results

171

172 Relative abundance of insect groups

173 
174 In total 325 to 2339 insects were counted per garden centre (Table 2). The overall insect profile

175 varied among garden centres, but was generally similar to what was previously recorded on

176 plants growing in gardens in East Sussex (Garbuzov \& Ratnieks, 2014b; Garbuzov, Samuelson

$177 \&$ Ratnieks, 2015). Bees were the most abundant group (mean 50.9\%, range 16.9-64.7\%, Table

178 2) in five of the six garden centres, followed by flies (mean 43.1\%, range 28.0-78.6\%), of which

179 syrphid flies were always more common than the non-syrphid flies. Butterflies and moths were 180 generally less abundant (mean $3.2 \%$, range $0.1-14.5 \%$ ), as were wasps (mean $2.7 \%$, range 0.2 -

$18111.3 \%$ ). Other insect types were recorded in only one of six garden centres and comprised only $0.8 \%$ of the counts (Wyevale) and were all longhorn beetles (Coleoptera: Cerambycidae).

Consistency with previous studies

The attractiveness of five plant species or genera that were common between this study and two previous studies of plants in gardens in East Sussex was in broad agreement (Table S1; Fig. 2).

The percentile rank recorded in this study correlated significantly with that in a previous study of 32 plant varieties on the University of Sussex campus in Falmer $(r=0.92, P=0.026$, Garbuzov \& Ratnieks, 2014b) and a survey of 79 plant varieties in a park in Lewes $(r=1.00, P=0.004$,

Garbuzov, Samuelson \& Ratnieks, 2015). Similarly, mean insect count per $\mathrm{m}^{2}$ on the same plants in this study correlated significantly with that in the previous study in Falmer $(\mathrm{r}=0.99, \mathrm{P}=$ 0.001, Garbuzov \& Ratnieks, 2014b) and marginally non-significantly in the previous study in Lewes $(\mathrm{r}=0.91, \mathrm{P}=0.089$, Garbuzov, Samuelson \& Ratnieks, 2015). 
198 In all six garden centres most varieties on sale were relatively unattractive to insects. Frequency

199 distributions of variety attractiveness in each garden centre were highly positively skewed, with

200 most varieties (mean 68\%, range 33-97\%) attracting $0-5$ insects per count per $\mathrm{m}^{2}$ (Fig. 3).

201 Fewer varieties (mean 13\%, range 1-22\%) attracted 5 - 10 insects or $>10$ insects (mean 19\%,

202 range $1-48 \%$ ) per count per $\mathrm{m}^{2}$.

203

When attractiveness is expressed as marjoram scores the pattern is similar. On average

$67 \%$ (range 53-88\%) of varieties had marjoram scores between $0-0.25$ (Fig. 3), 18\% (range 7 -

205

$33 \%$ ) between $0.25-0.5$ and $15 \%$ (range $4-24 \%$ ) greater than 0.5 . On average, only $4 \%$ (range

$0-7 \%$ ) of varieties had a marjoram score greater than 1 , i.e. were more attractive than marjoram.

207

208

Are recommended varieties better than non-recommended?

209

210

Marjoram scores were significantly associated with whether or not the plants have been

211 recommended as bee- or pollinator-friendly (Kruskal-Wallis test, $\mathrm{K}=54.99$, $\mathrm{df}=2, \mathrm{P}<0.001$,

212 Fig. 4). Post-hoc pairwise comparisons showed that both (1) varieties on the RHS Perfect for

213 Pollinators list (median = 0.21, IQR: 0.05-0.46; Wilcoxon-Mann-Whitney test, $\mathrm{U}=11668.00, \mathrm{P}$

$214<0.001)$ and $(2)$ varieties with a bee- or insect-friendly symbol on pot or label (median $=0.21$,

215 IQR: 0.06-0.40, Wilcoxon-Mann-Whitney test, $\mathrm{U}=7377.50, \mathrm{P}<0.001$ ) were more attractive

216 than varieties with no recommendation (median $=0.05$, IQR: $0.00-0.15)$, corresponding to a

217 median increase of $320 \%$. However, varieties in the two recommended categories were not

218 different from each other (aggregate median =0.21, aggregate IQR: 0.05-0.45, Wilcoxon-Mann-

219 Whitney test, $\mathrm{U}=6138.00, \mathrm{P}=0.931)$. 
Are multi-year plants more attractive than bedding plants?

222

223 Multi-year plants (median $=0.13$, IQR: 0.03-0.37) had significantly higher marjoram scores than

224 bedding plants (median =0.08, IQR: 0.00-0.17; Wilcoxon-Mann-Whitney test, $\mathrm{U}=13986, \mathrm{P}=$

2250.006 , Fig. 5), corresponding to a median increase of $63 \%$. However, long tails in the

226 distributions of both plant groups meant that most multi-year plants (320 of 335, 96\%) and

227 bedding plants ( 66 of $69,96 \%$ ) were less attractive than the marjoram control.

228

229

\section{Discussion}

230

Most varieties were relatively unattractive to flower-visiting insects

232

233 The majority of plant varieties in each garden centre were relatively unattractive to flower-

234 visiting insects, with the frequency distributions of attractiveness strongly skewed to the right

235 (Fig. 3). Similar patterns were seen in the distributions of both actual insect counts and marjoram scores. These results are also very similar to those obtained in an earlier survey of 79 plant varieties in a public park in the same region (Garbuzov, Samuelson \& Ratnieks, 2015) indicating that this pattern is likely to be general. Indeed, the distributions are expected to be similar if the plants procured by park managers are chosen without regard to their attractiveness to flowervisiting insects. Therefore, the results strongly suggest that there is considerable scope for making parks and gardens considerably more insect-friendly through making more judicious

242 choices of the varieties to be grown. Although insect-attractive varieties are relatively few, our 
243 survey identified a number of them, some of which are not included on the RHS 'Perfect for

244 Pollinators' list or marked by a pollinator-friendly label (e.g. Iberis 'Masterpiece', Alstromeria

245 'Inticancha Dark Purple' and Tradescantia 'Blue and Gold', Table S2).

246 Although most flower-visiting insects are generalists visiting a wide range of plant

247 species, some are specialists dependent on one or a few related plant species or genera. These

248 plants will not necessarily attract a wide range of insects in large numbers, and as such may not

249 be considered attractive, but they can have a place in gardens, especially if they are aesthetically

250 pleasing and could offer an opportunity to observe and aid insects that are of special interest or

251 are rare (Garbuzov \& Ratnieks, 2014a).

252

253 Current advice on pollinator-friendliness is imperfect

254

255 Our results showed that the median attractiveness of varieties with a bee- or pollinator-friendly

256 symbol on the label, or those present on the RHS 'Perfect for Pollinators' list, was 4.2 times

257 greater than of varieties without such recommendations. However, given the large range and

258 spread of varieties in each category, there was considerable overlap between the three

259 distributions (Fig. 4). In other words, there were many recommended varieties that were

260 unattractive or poorly attractive to insects, and some non-recommended varieties that were very

261 attractive (Table S2). Thus, the use of the word "perfect" by the RHS list is inaccurate and

262 presumably was chosen for marketing reasons. Nonetheless, the recommended plants were about

2634 times more attractive to flower-visiting insects, which is a step in the right direction that could

264 further be improved by greater reliance on empirical data, as this becomes available. However,

265 given the two orders of magnitude range in attractiveness typically seen among ornamental 
266 plants (this study, Garbuzov \& Ratnieks, 2014b; Garbuzov, Samuelson \& Ratnieks, 2015), a

267 three-fold median difference between recommended and non-recommended varieties could

268 potentially be greatly improved. Additionally, the plant labels themselves are not always

269 accurate. For example, the label on the patio rose 'Glowing Pink' showed flowers with a large

270 area of insect-rewarding plant parts in the centre, while the actual flowers on the plant looked

271 markedly different - closed with excessive number of petals (Fig. 6).

272 Pollinator-friendly recommendations are generally based on anecdotal experiences and

273 opinions, rather than on empirical evidence (Garbuzov \& Ratnieks, 2014a), which reduces their

274 value. However, given the tens of thousands of varieties in existence, and the variability of the

275 natural world, it is doubtful that any list of recommendations can be definitive. Furthermore,

276 recommendations are often given at a level that is too broad. For example, the RHS 'Perfect for

277 Pollinators' list recommends “Aster species and hybrids" (RHS, 2014), implying that all species,

278 hybrids and varieties are equally good for pollinators. However, even within this one group of

279 plants, the hundreds of different species, hybrids and varieties available to gardeners are hugely

280 variable in their attractiveness to flower-visiting insects (Garbuzov \& Ratnieks, 2015).

Multi-year plants are slightly more attractive than bedding plants

284 Our results show that the median attractiveness of multi-year plants is 1.6 times greater than that 285 of bedding plants. Perennials are generally characterized by higher levels of assimilated

286 resources than annuals, and hence the higher amounts are generally allocated to sexual

287 reproduction and pollinator reward (Corbet, 1995). There is some evidence that the abundance of

288 certain bee families, Apidae, Megachilidae and Anthophoridae, is positively associated with 
289 plant communities dominated by perennial, as opposed to annual plants, as is characteristic of

290 later successional stages (Parrish \& Bazzaz, 1979; Fussell \& Corbet, 1992; Steffan-Dewenter \&

291 Tscharntke, 2001).

292

293

Garden centres are valuable sources of data

294

295

Our results show that flower-visiting insects are attracted in large numbers to plants in full bloom on display for sale to customers in garden centres (Table 2). The most common insect groups seen visiting flowers were bees (predominantly honey and bumble bees) and flies (predominantly hover flies, Syrphidae), in agreement with surveys of insects on plants in gardens in the same region (Table 2, Garbuzov \& Ratnieks, 2014b; Garbuzov, Samuelson \& Ratnieks, 2015). The relative attractiveness of plant varieties was also consistent with that from two previous surveys of plants growing in gardens (Garbuzov \& Ratnieks, 2014b, Garbuzov, Samuelson \& Ratnieks, 2015). Percentile ranks of five plant species or groups that were in common between this survey and the previous surveys (Table S1) showed significant correlations close to a 1:1 ratio (Fig. 2a), although these correlations were not expected to be perfect or near $1: 1$, as the assemblages of plants in each survey were different and insect abundance and diversity would also have differed. Nonetheless, the percentile rank correlations showed that certain plants tended to be among the most attractive (Origanum, Nepeta, openflowered Dahlia varieties), moderately attractive (Lavandula), or least attractive (Pelargonium) whether on sale in a garden centre in pots or growing in a garden. Correlations in the absolute mean insect counts per unit area were also strong and significant $(\mathrm{P}=0.001$, Garbuzov \&

311 Ratnieks, 2014b) or marginally non-significant $(\mathrm{P}=0.089$, Garbuzov, Samuelson \& Ratnieks, 
312 2015) between this survey and the two previous surveys, although considerably below 1:1 (Fig.

313 2b), perhaps because plants in pots attract fewer insects than those established in the ground.

314 Importantly, this shows that plants on sale in garden centres can be surveyed in a

315 meaningful way in relation to plants growing in gardens. In addition, our survey shows that

316 garden centres sell a wide range of ornamental flowering plants varieties, most of which are in

317 full bloom as they are displayed for sale. This is presumably because bloom is the main feature

318 of interest to the customers. However, it is also convenient for conducting surveys of insects

319 visiting flowers.

320

321 Conclusions

322

323

Our study showed that most flowering varieties being sold to the public in England are

324

relatively unattractive to flower-visiting insects. If most private gardeners obtain most of their

garden plants from garden centres, then, on the whole, urban gardens are probably not as friendly

to flower-visiting as they could potentially be. There is considerable scope for making gardens

more insect-friendly through judicious choices of varieties that are grown. We have also shown

that the plants recommended as friendly to pollinators are only a few times better than the plants

that are not recommended, presumably because these recommendations generally rely on casual

observations or opinions, and could further be improved by greater reliance on more rigorous

empirical data. Although being a few times better is a step in the right direction for

recommended varieties, given the c. 100-fold range in attractiveness among garden plants, there

valuable sources of data, as they sell a wide range of ornamental flowering plant varieties, most 
335 of which are in full bloom when sold. The insect-attractiveness data gathered in garden centres,

336 where the plants are in pots, appear to be consistent with the data from parks and gardens, where

337 the plants are established in the ground.

338 We suggest there is also a scope for garden centres to be pro-active and take the initiative

339 by carrying out surveys to quantify the insect-attractiveness of plant varieties that they sell, as the

340 methods for doing so are relatively straightforward to follow, in order to make their pollinator-

341 friendly promotions more accurate and evidence-based. Furthermore, customers themselves

342 could make a few casual observations before a purchase, which, although not very accurate due

343 to stochasticity of insect counts, would give a rough indication of plant attractiveness. Thus,

344 customers could exert consumer pressure by creating more demand for varieties attractive to

345 flower-visiting insects, which garden centres could potentially respond to. Garden centres could

346 also use this information to increase the proportion of insect-friendly varieties that are offered for

347 sale, and thus help pollinators in gardens in the wider environment.

348

349 Acknowledgements

350

351 We are grateful to Zoe Bruce (Garden Pride), John Leonard (Wyevale), Phil Cottingham

352 (Staverton Nursery), Graham Gough (Marchants Hardy Plants), Michael Edmondson (Hillier), 353 and John Paisley (Wych Cross) for their assistance and for allowing us to carry out our surveys 354 in the garden centres under their management.

355

356

References

357 
358 Baldock KCR, Goddard MA, Hicks DM, Kunin WE, Mitschunas N, Osgathorpe LM, Potts SG,

359 Robertson KM, Scott AV, Stone GN, Vaughan IP, and Memmott J. 2015. Where is the

360

361

362

363

364

365

366

367

368

369

370

371

372

373

374

375

376

377

378

379

380

UK's pollinator biodiversity? The importance of urban areas for flower-visiting insects.

Proceedings of the Royal Society B - Biological Sciences 282. DOI:

$10.1098 / \mathrm{rspb} .2014 .2849$

Clark NE, Lovell R, Wheeler BW, Higgins SL, Depledge MH, Norris K. 2014. Biodiversity, cultural pathways, and human health: a framework. Trends in Ecology \& Evolution 29:198-204. DOI: 10.1016/j.tree.2014.01.009

Corbet SA. 1995. Insects, plants and succession: advantages of long-term set-aside. Agriculture, Ecosystems \& Environment 53:201-217. DOI: 10.1016/0167-8809(94)00581-X

Fussell M, and Corbet SA. 1992. Flower usage by bumble-bees: a basis for forage plant management. Journal of Applied Ecology 29:451-465. DOI: 10.2307/2404513

Garbuzov M, and Ratnieks FLW. 2014a. Listmania: the strengths and weaknesses of lists of garden plants to help pollinators. BioScience 64:1019-1026. DOI: 10.1093/biosci/biu150

Garbuzov M, and Ratnieks FLW. 2014b. Quantifying variation among garden plants in attractiveness to bees and other flower-visiting insects. Functional Ecology 28:364-374. DOI: $10.1111 / 1365-2435.12178$

Garbuzov M, and Ratnieks FLW. 2015. Using the British national collection of asters to compare the attractiveness of 228 varieties to flower-visiting insects. Environmental Entomology 44:638-646. DOI: $10.1093 / \mathrm{ee} / \mathrm{nvv037}$

Garbuzov M, Madsen A, and Ratnieks FLW. 2015. Patch size has no effect on insect visitation rate per unit area in garden-scale flower patches. Acta Oecologica 62: 53-57. DOI: 10.1016/j.actao.2014.12.002 
381 Garbuzov M, Samuelson EEW, and Ratnieks FLW. 2015. Survey of insect visitation of

382

383

384

385

386

387

388

389

390

391

392

393

394

395

396

397

398

399

400

401

402

ornamental flowers in Southover Grange garden, Lewes, UK. Insect Science 22:700-705.

DOI: $10.1111 / 1744-7917.12162$

Ghazoul J. 2015. Qualifying pollinator decline evidence. Science 348:981-982. DOI: 10.1126/science.348.6238.981-b

Goddard MA, Dougill AJ, and Benton TG. 2010. Scaling up from gardens: biodiversity conservation in urban environments. Trends in Ecology \& Evolution 25:90-98. DOI: 10.1016/j.tree.2009.07.016

Goddard MA, Dougill AJ, and Benton TG. 2013. Why garden for wildlife? Social and ecological drivers, motivations and barriers for biodiversity management in residential landscapes. Ecological Economics 86:258-273. DOI: 10.1016/j.ecolecon.2012.07.016

Goulson D, Nicholls E, Botías C, and Rotheray EL. 2015. Bee declines driven by combined stress from parasites, pesticides, and lack of flowers. Science 347:1255957. DOI: $10.1126 /$ science. 1255957

Kennedy CM, Lonsdorf E, Neel MC, Williams NM, Ricketts TH, Winfree R, Bommarco R, Brittain C, Burley AL, Cariveau D, Carvalheiro LG, Chacoff NP, Cunningham SA, Danforth BN, Dudenhöffer J-H, Elle E, Gaines HR, Garibaldi LA, Gratton C, Holzschuh A, Isaacs R, Javorek SK, Jha S, Klein AM, Krewenka K, Mandelik Y, Mayfield MM, Morandin L, Neame LA, Otieno M, Park M, Potts SG, Rundlöf M, Saez A, SteffanDewenter I, Taki H, Viana BF, Westphal C, Wilson JK, Greenleaf SS, and Kremen C. 2013. A global quantitative synthesis of local and landscape effects on wild bee pollinators in agroecosystems. Ecology Letters 16:584-599. DOI: 10.1111/ele.12082 
403 Lindemann-Matthies P, Marty T. 2013. Does ecological gardening increase species richness and 404 aesthetic quality of a garden? Biological Conservation 159: 37-44. DOI:

405 10.1016/j.biocon.2012.12.011

406

407

408

409

410

411

412

413

414

415

416

417

418

419

420

421

422

423

424

Mew H, Robinson C, Humphrey A, Kafka E, Oliver R, and Bose S. 2003. Housing in England 2001/2. A report of the 2001/2 Survey of English Housing carried out by the National Centre for Social Research on behalf of the Office of the Deputy Prime Minister. Housing Data and Statistics Division, Office of the Deputy Prime Minister, London.

Parrish JAD, and Bazzaz FA. 1979. Difference in pollination niche relationships in early and late successional plant communities. Ecology 60:597-610. DOI: 10.2307/1936080

Potts SG, Biesmeijer JC, Kremen C, Neumann P, Schweiger O, and Kunin WE. 2010. Global pollinator declines: trends, impacts and drivers. Trends in Ecology \& Evolution 25:345353. DOI: $10.1016 /$ j.tree.2010.01.007

RHS: Royal Horticultural Society. 2014. Perfect for Pollinators plant list. Available at https://www.rhs.org.uk/science/pdf/conservation-and-

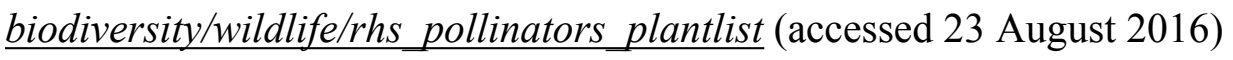

RHS: Royal Horticultural Society. 2016. RHS Plant Finder. Available at https://www.rhs.org.uk/plants (accessed 15 November 2016)

Ryall C, and Hatherell P. 2003. A survey of strategies adopted by UK Wildlife Trusts in the promotion of gardening for wildlife. Environmentalist 23:81-87. DOI: 10.1023/a:1022995610486

Salisbury A, Armitage J, Bostock H, Perry J, Tatchell M, and Thompson K. 2015. Enhancing gardens as habitats for flower-visiting aerial insects (pollinators): should we plant native 

2664.12499

427 Shackleton K, and Ratnieks FLW. 2016. Garden varieties: How attractive are recommended 428 garden plants to butterflies? Journal of Insect Conservation 20:141-148. DOI: $10.1007 / \mathrm{s} 10841-015-9827-9$

Shanahan DF, Fuller RA, Bush R, Lin BB, Gaston KJ. 2015. The health benefits of urban nature: how much do we need? BioScience 65: 476-485. DOI: 10.1093/biosci/biv032

432 Steffan-Dewenter I, and Tscharntke T. 2001. Succession of bee communities on fallows.

433 Ecography 24:83-93. DOI: 10.1034/j.1600-0587.2001.240110.x

434 Wyevale. 2015. Wyevale Garden Centres Capital Limited: Report and Financial Statements.

435 Available at http://www.wyevalegardencentres.co.uk/media/HKQ/file/Wyevale-Annual- 


\section{Table $\mathbf{1}$ (on next page)}

Table 1. General information on the five garden centres and one nursery surveyed, and the plant information summary. 
Table 1. General information on the five garden centres and one nursery surveyed, and the plant information summary Name

Garden Pride
Wyevale Staverton Marchants Hillier Wych Cross

\section{(A) Business information}

Address

Dates surveyed in 2015

Type of business

Total number of stores (all in UK)

\section{(B) Plant information}

Number of plant varieties surveyed

Total area of varieties surveyed $\left(\mathrm{m}^{2}\right)$

Proportion of plant varieties with a recommendation ${ }^{2}$

On RHS Perfect for Pollinators list

With a bee- or pollinator-friendly symbol on pot or label

No recommendation

Plant varieties by type ${ }^{3}$

Multi-year

Bedding

Overall garden centre attractiveness

\section{Mean marjoram score ${ }^{4}$ per variety \\ Median marjoram score ${ }^{4}$ of} varieties

Proportion of plants better than marjoram

$\begin{array}{cc}\begin{array}{c}\text { Common } \\ \text { Lane, } \\ \text { Ditchling, } \\ \text { BN6 8TP }\end{array} & \begin{array}{c}\text { A22 Lower } \\ \text { Dicker, } \\ \text { Hailsham, } \\ \text { BN27 4BJ }\end{array} \\ \begin{array}{c}\text { 08-09 July } \\ \text { Medium } \\ \text { chain } \\ \text { garden } \\ \text { centre }\end{array} & \begin{array}{c}\text { Large chain } \\ \text { garden centre }\end{array}\end{array}$

18

68

69

34.1

$46 \%$

$18 \%$

$49 \%$

$88 \%$

$12 \%$

153

Eastbourne
Road,
Halland,
BN8 6PU
29-30 July
Independent
garden
centre

2 Marchants

Cottages, Mill

Lane,

Laughton,

BN8 6AJ

07-08 August

Independent

nursery and garden

1

1

74

16.9

59

66

30.4

$38 \%$

$59 \%$

$7 \%$

$41 \%$

$46 \%$

$88 \%$

$12 \%$

0.25

0.20

0.32

0.36

0.18

0.11

0.20

$0 \%$

$7 \%$

$7 \%$

Road, Stone

Cross,

Pevensey,

BN24 5BS

09-10

September

Medium

garden

centre

Forest Row, RH18

$5 \mathrm{JW}$

18-19 September

Independent ${ }^{1}$ garden centre

12

1

14.7

27.6

$59 \%$

$24 \%$

$39 \%$

$7 \%$
$99 \%$

$83 \%$

$17 \%$

$92 \%$

$8 \%$

${ }^{1}$ Shortly after our survey, in October 2015, the independent Wych Cross garden centre was acquired by the Wyevale garden centre chain.

${ }^{2}$ Recommendations by the RHS list and symbols on pots or labels overlapped, so the three proportions do not add up to $100 \%$.

${ }^{3}$ Multi-year plants included fully hardy perennials, biennials and shrubs; bedding plants included annuals, as well as half-hardy and tender biennials and perennials.

${ }^{4}$ Insect count per $\mathrm{m} 2$ relative to marjoram, Origanum vulgare, two patches of which were brought in and set up by the researchers at each location as a benchmark. 


\section{Table 2 (on next page)}

Table 2. Finer breakdown of flower-visiting insect counts in eight main categories. 
Table 2. Finer breakdown of flower-visiting insect counts in eight main categories

\begin{tabular}{|c|c|c|c|c|c|c|}
\hline & $\begin{array}{c}\text { Garden } \\
\text { Pride }\end{array}$ & Wyevale & Staverton & Marchants & Hillier & $\begin{array}{l}\text { Wych } \\
\text { Cross }\end{array}$ \\
\hline \multicolumn{7}{|l|}{ Bees } \\
\hline Honey bees, Apis mellifera & 49 & 2 & 36 & 812 & 508 & 576 \\
\hline \multicolumn{7}{|l|}{ Bumble bees, Bombus spp. ${ }^{1}$} \\
\hline B. terrestris/lucorum group & 88 & 53 & 524 & 13 & 40 & 42 \\
\hline B. hortorum group & 6 & - & 1 & 7 & - & 5 \\
\hline B. pratorum group & 4 & - & 5 & 8 & - & 0 \\
\hline B. lapidarius group & - & - & 10 & - & - & 0 \\
\hline B. pascuorum group & 23 & 3 & 43 & 19 & 86 & 416 \\
\hline All bumble bees & 121 & 56 & 583 & 47 & 126 & 463 \\
\hline Other bees & 16 & 5 & 16 & 79 & 28 & 216 \\
\hline All bees & 186 & 63 & 635 & 938 & 662 & 1255 \\
\hline \multicolumn{7}{|l|}{ Flies } \\
\hline Hover flies & 79 & 212 & 284 & 374 & 308 & 639 \\
\hline Other flies & 12 & 81 & 34 & 238 & 146 & 396 \\
\hline All flies & 91 & 293 & 318 & 612 & 454 & 1035 \\
\hline \multicolumn{7}{|l|}{ Butterflies \& moths } \\
\hline Thymelicus sylvestris & 4 & - & - & - & - & - \\
\hline Ochlodes sylvanus & 1 & - & - & - & - & - \\
\hline Pieris rapae & - & - & 2 & - & - & - \\
\hline Pieris brassicae & - & - & 1 & - & - & - \\
\hline Aglais io & - & - & 1 & - & - & - \\
\hline Aglais urticae & 40 & - & - & - & - & - \\
\hline Vanessa atalanta & - & - & - & - & 1 & 6 \\
\hline Polygonia c-album & 1 & 1 & - & 3 & - & - \\
\hline Maniola jurtina & 1 & 11 & - & - & - & 2 \\
\hline Pararge aegeria & - & - & - & - & - & 6 \\
\hline Moths & - & 1 & - & - & - & - \\
\hline $\begin{array}{l}\text { All butterflies \& moths } \\
\text { Wasps }\end{array}$ & 47 & 13 & 4 & 3 & 1 & 14 \\
\hline $\begin{array}{l}\text { Social wasps, Hymenoptera: } \\
\text { Vespinae }^{2}\end{array}$ & - & - & 23 & 182 & 1 & 15 \\
\hline $\begin{array}{l}\text { Other wasps, non-social } \\
\text { apocrite Hymenoptera, } \\
\text { excluding bees, ants and } \\
\text { sawflies }\end{array}$ & 1 & 1 & 1 & 15 & 1 & 20 \\
\hline \multicolumn{7}{|l|}{ Other } \\
\hline Beetles, Coleoptera & - & 3 & - & - & - & - \\
\hline All insects & 511 & 436 & 1616 & 2688 & 1781 & 3594 \\
\hline
\end{tabular}

${ }^{1}$ Bumble bee identification groups follow Fussell \& Corbet (1992)

${ }^{2}$ Social wasp species are not confined to Vespinae, but vespine wasps are the only social wasps that occur in Britain 


\section{Figure 1 (on next page)}

Examples of some pollinator-friendly logos found on plant labels in garden centres.

(a) RHS Perfect for Pollinators, (b) non-RHS Perfect for Pollinators, (c, d) Bee friendly, (e) Good for honey bees, (f) Bee and butterfly images. 

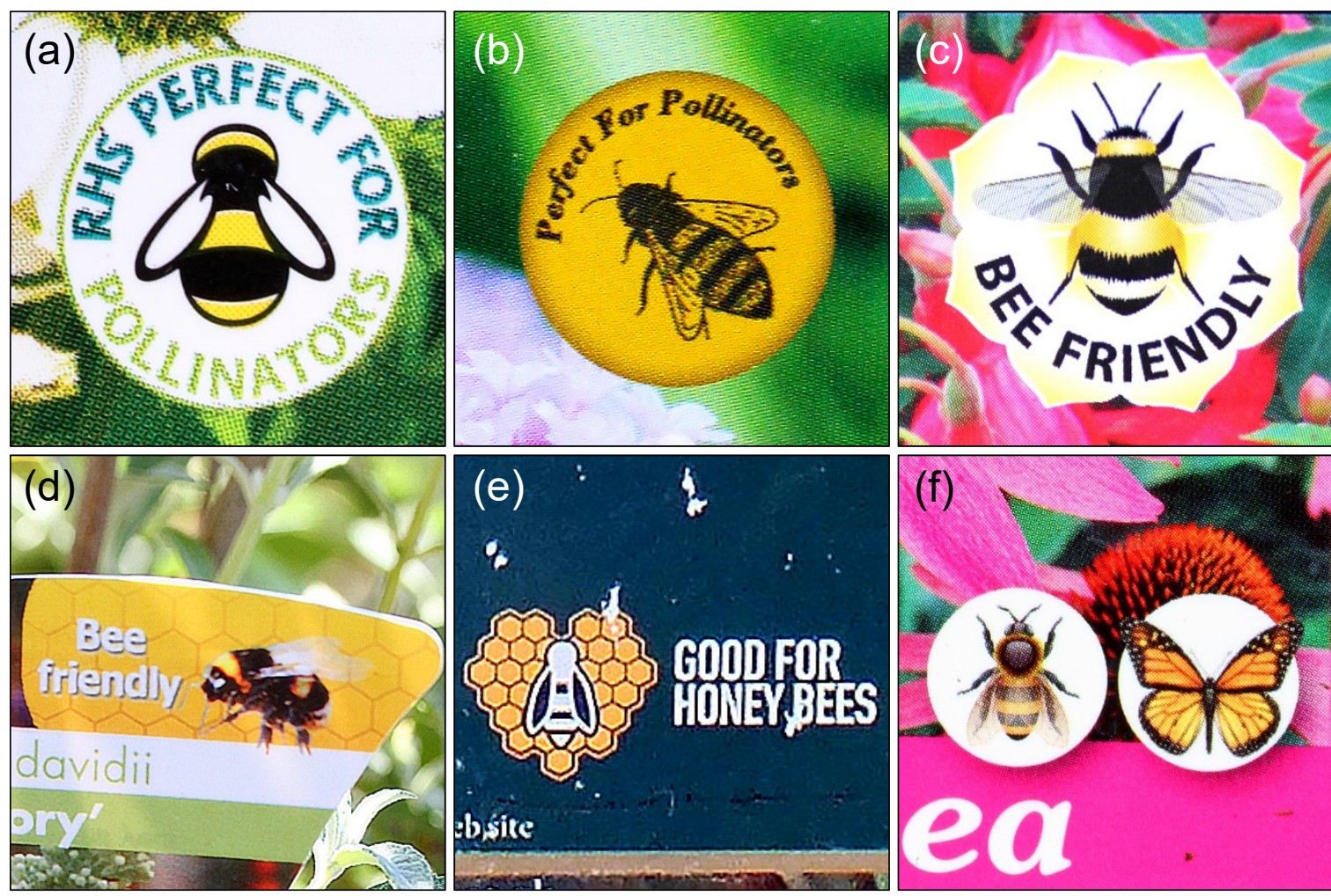
Figure 2 (on next page)

Consistency with previous studies.

Correlations of (a) percentile rank and (b) mean insect count per $\mathrm{m}^{2}$ between plant varieties surveyed in this study and two previous studies conducted in Falmer (closed circles and solid line, Garbuzov \& Ratnieks, 2014b) and Lewes (open circles and dotted line, Garbuzov, Samuelson \& Ratnieks, 2015), all in East Sussex, England. Dashed line is the identity line, $y=$ $x$. 
(a)

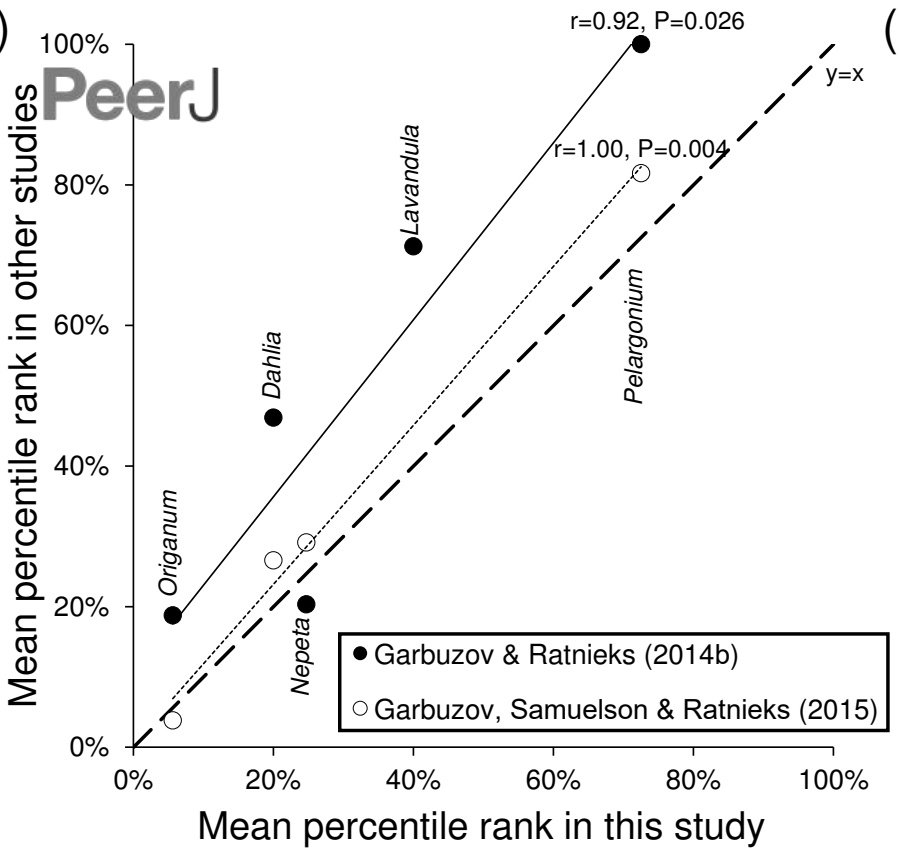

(b)

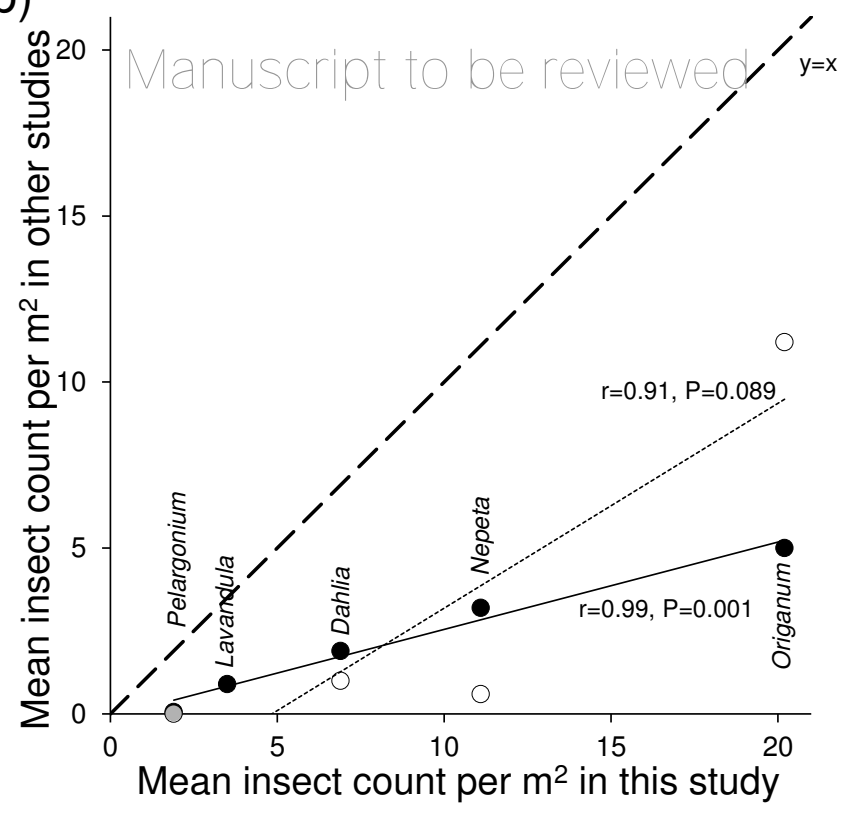




\section{Figure 3 (on next page)}

Frequency distributions of insect-attractiveness of plant varieties in the six garden centres surveyed.

Frequency distributions of insect-attractiveness of plant varieties in the six garden centres surveyed, based on the mean numbers of insects per count per $\mathrm{m}^{2}$ (a-f) and on the mean counts per $\mathrm{m}^{2}$ relative to marjoram, Origanum vulgare ( $\left.\mathrm{g}-\mathrm{I}\right)$. Proportions of varieties in each bin are coloured according to recommendation: RHS Perfect for Pollinators list (orange), beeor pollinator-friendly symbol on pot or label (bluish green), or both (sky blue); remaining varieties without a recommendation are coloured in black. 


\section{0 (a) Recommendations}

60

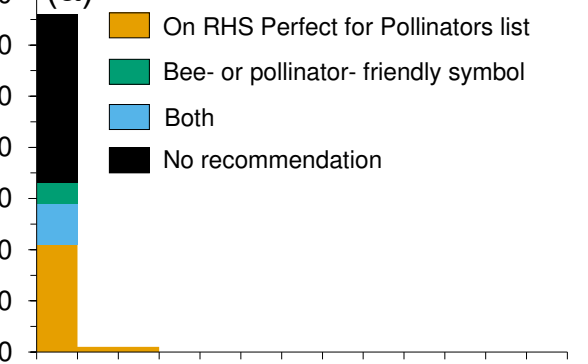

70

(b)

boetry

50

40

30

20

10

0

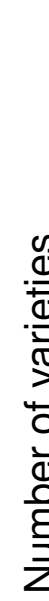

] (c)

60

60

40

() 30

20

10

(d)

$\begin{array}{ll}\text { ڤે } & 60 \\ \text { ह } & 50 \\ \text { 乙 } & 40\end{array}$

30

20

10

0

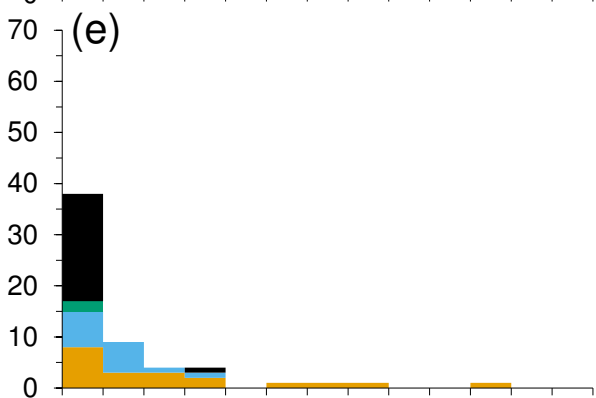

0

70 _f

60 Peer) reviewing PDF | (2016:08:12859:1:1:NEW 28 an 2017)

50

40

30

20

10

0

0

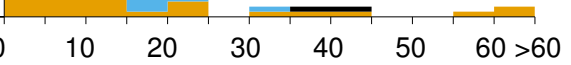

Mean number of insects per count per $\mathrm{m}^{2}$

(g)

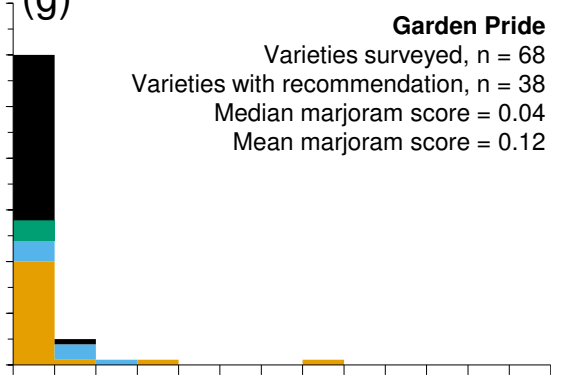

(h) Manusc ript tovareties surveyed, $n=69$

Varieties with recommendation, $\mathrm{n}=26$

Median marjoram score $=0.06$

Mean marjoram score $=0.25$

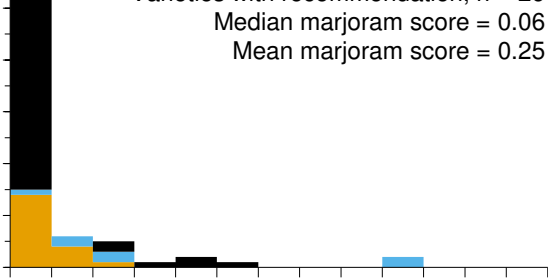

(i)

Staverton Nursery

Varieties surveyed, $n=68$

Varieties with recommendation, $n=40$

Median marjoram score $=0.11$

Mean marjoram score $=0.20$
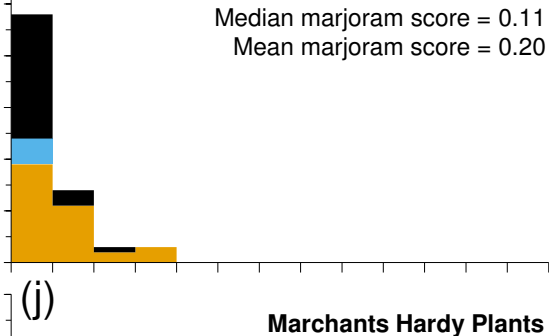

Varieties surveyed, $n=74$

Varieties with recommendation, $\mathrm{n}=46$

Median marjoram score $=0.20$

Mean marjoram score $=0.32$

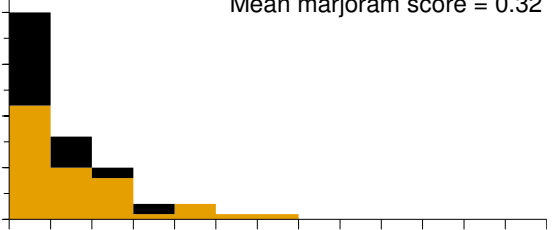

$(k)$

Hillier

Varieties surveyed, $\mathrm{n}=59$

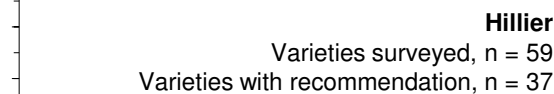

Median marjoram score $=0.18$

Mean marjoram score $=0.36$
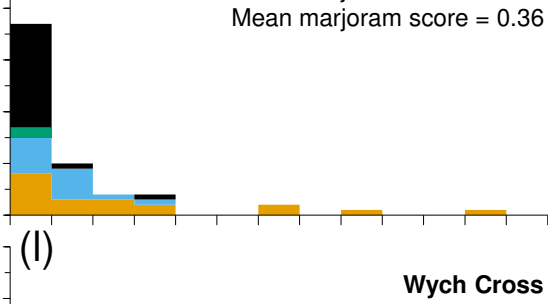

Varieties surveyed, $\mathrm{n}=66$

Varieties with recommendation, $\mathrm{n}=40$

Median marjoram score $=0.18$

Mean marjoram score $=0.33$

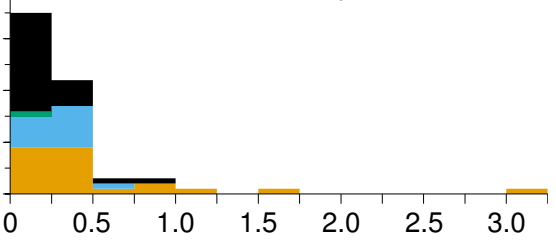

Mean marjoram score 


\section{Figure 4 (on next page)}

Boxplots of mean marjoram scores of varieties according to recommendation category.

Lowercase letters above boxplots denote homogeneous subsets based on pairwise comparisons using the Wilcoxon-Mann-Whitney median comparison test ( $\alpha=0.05)$, where categories not sharing a letter are significantly different. 


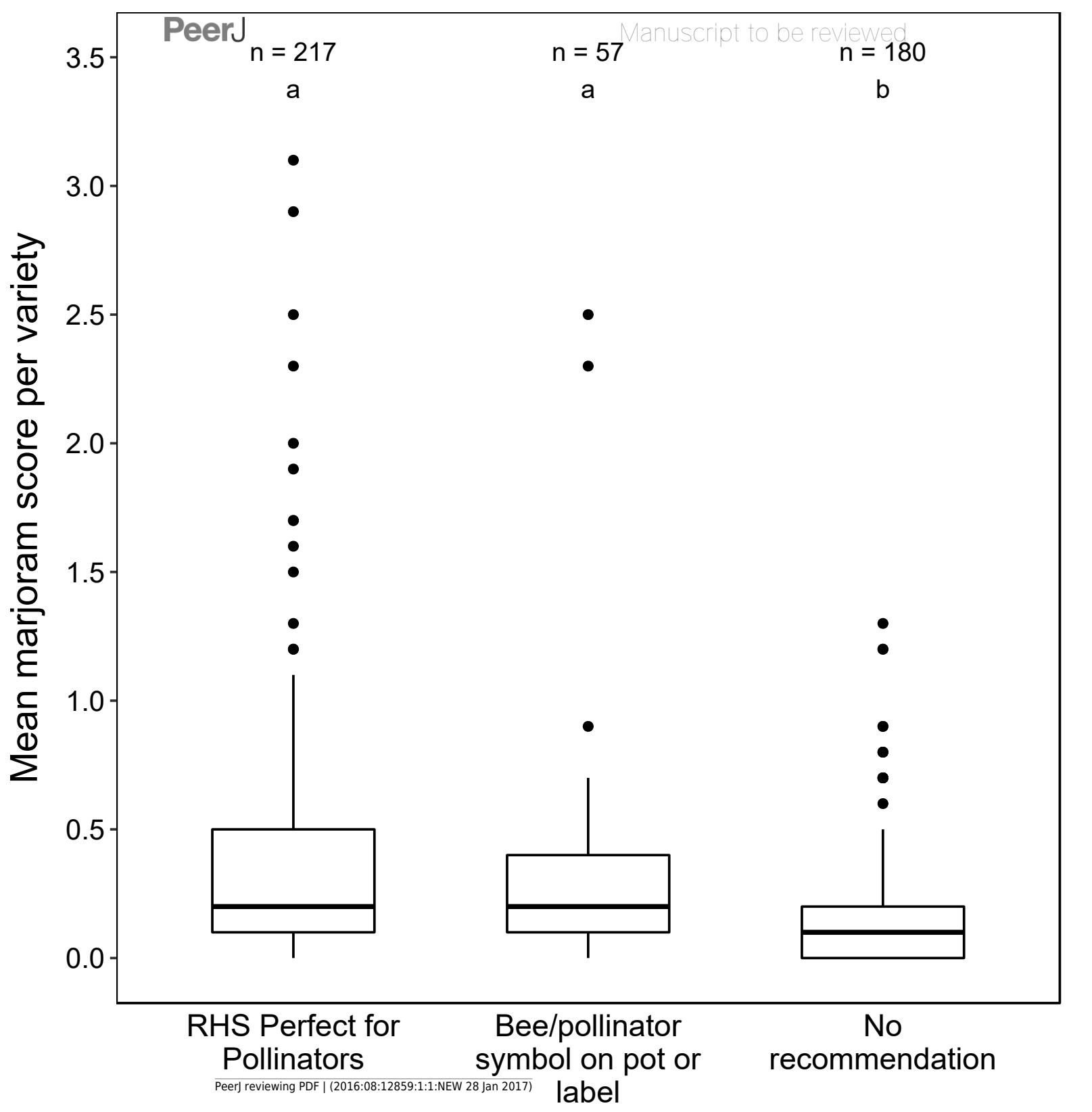




\section{Figure 5(on next page)}

Boxplots of mean marjoram scores of varieties in the two plant longevity categories.

Multi-year plants were defined as plants that are typically grown for more than one season in Britain, which includes shrubs and fully-hardy herbaceous perennials. Bedding plants were defined as plants that are typically grown for only one season, which includes annuals, as well as tender and half-hardy biennials and perennials. Data are aggregated from all six study locations. 



\section{Table 3(on next page)}

Discrepancy between plants and their labels.

Patio rose 'Glowing Pink', with the flower displayed on the label (a) considerably different from the actual flowers on the plant (b). 


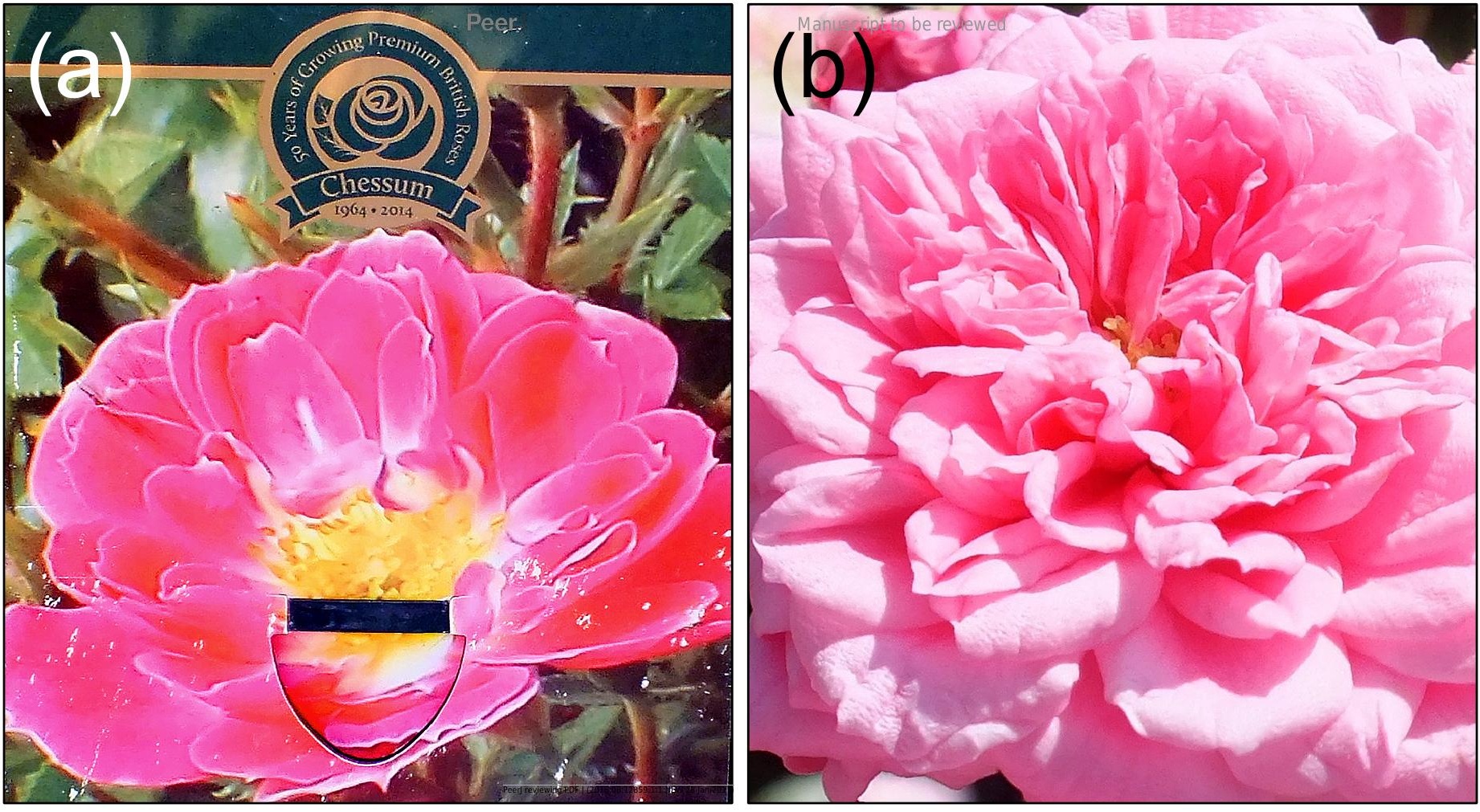

